\title{
O MESMO, OS OUTROS E O "ELES" ALGUMAS NOTAS SOBRE OS §§ 25-27 DE SEIN UND ZEIT
}

Vasco Baptista Marques ${ }^{1}$

RESUMO: As palavras que se seguem constituem uma tentativa de explorar os diversos sentidos que revestem a figura do "com» [mit], tal como surge configurada ao longo dos §§ 25-27 de Sein und Zeit ${ }^{2}$. Escutaremos atentamente aquilo que Heidegger tem a dizer a respeito da necessária determinação do ser-no-mundo [in-der-Welt-sein] como ser-com [Mitsein] e veremos, depois, em que medida a sua analítica existencial faz (ou não) depender a constituição do ser-si-mesmo [Selbstsein] da figura do outro. Por último, e em jeito de conclusão, tentaremos mostrar como Heidegger articula a interrogação pela ipseidade ou pelo «quem?» [Wer?] do ser-aí quotidiano [alltägliche Dasein], com uma breve reflexão acerca da inautenticidade [Uneigentlichkeit] fáctica em que o mesmo muitas vezes parece soçobrar. Será então, estamos em crer, o momento apropriado para debatermos o significado da controversa noção heideggeriana de "eles» [das Man], aproveitando também o ensejo para lançarmos a questão relativa à responsabilidade (ética?) do Dasein. Metodologicamente, contornaremos (sempre que possível) os tradicionais comentários a respeito das infinitas modalidades alternativas de tradução do jargão filosófico heideggeriano.

PALAVRAS-CHAVE: Outros. Eles. Ser-aí. Com. Mundo. Responsabilidade.

\section{Dasein como ser-no-mundo}

A questão que norteia toda a investigação levada a cabo por Heidegger, ao longo dos §§ 25-27 de Sein und Zeit, é a seguinte: quem é o Dasein, na sua

\footnotetext{
${ }^{1}$ Centro de Filosofia da Universidade de Lisboa. Email: vascobmarques@hotmail.com ${ }^{2}$ HEIDEGGER, Martin. Gesamtausgabe. Frankfurt am Main: Vittorio Klostermann, 1977. v. II, Sein und Zeit, §§ 25-27, 113-130, p. 152-173 (Being And Time, Trad. John Macquarrie \& Edward Robinson, Oxford/Cambridge: Blackwell, 2001).
} 
quotidianeidade [Alltäglichkeit] ${ }^{3}$ ? Questiona-se, aqui, pelo «quem?» desse Dasein que é; questiona-se, então, pela sua ipseidade [Ichheit]. Ora, tal como bem mostrou Heidegger, quando dos momentos inaugurais da sua análise preparatória do Dasein ${ }^{4}$, aquele que é encontra-se ontologicamente precedido por um a priori omni-englobante, que lhe confere a possibilidade geral de $\operatorname{ser}^{5}$. Essa estrutura ontológica fundamental em-função-da-qual [Worumwillen] o Dasein é, e no âmbito da qual se determina como ser-em [In-sein], é o próprio mundo - o que, por sua vez, nos obriga a tematizar o Dasein a partir do seu ser-no-mundo como Da-Sein: ser-aí. Porém, e de acordo com Heidegger, o «ser-no» da expressão «ser-no-mundo» não pretende, em caso algum, designar a relação estabelecida entre um continente (aquilo que contém) e um conteúdo (aquilo que é contido), mas sim a relação de radicação daquele que é, no contexto de uma estrutura ontológica de sentido que possibilita e condiciona todas as relações ônticas em geral:

\begin{abstract}
Ser-em [...] é um estado do Ser do Dasein; é um existencial. Assim, não se pode pensá-lo como o Estar-presente-à-mão [vorhandensein] de alguma Coisa corpórea [...] "num" ente que está presente-à-mão [vorhanden]. [...] "Em" [in] deriva de "innan" - "residir", "habitare" [...]. "An" significa "estou acostumado", "estou familiarizado com" [...]. O ente ao qual o Ser-em neste sentido pertence é aquele que caracterizámos como o ente que, em qualquer caso, eu próprio sou [bin]. A expressão "bin" está ligada a "bei" e, assim, "ich bin" [eu sou] quer dizer, por sua vez, "eu resido" ou "habito junto" ao mundo $[\ldots]^{6}$.
\end{abstract}

Ser é, então, ser-em (um mundo). Sempre que digo «eu sou» digo, tacitamente, a minha copertença a esse mundo em que sou. Entretanto, quem é esse de quem se diz que é-no-mundo? Quem é, de facto, o eu da proposição "eu sou»? Quem é, enfim, esse Dasein que eu próprio sou? A fim de respondermos a essas perguntas pelo «quem?» daquele que é, precisaremos, em primeira instância, de tomar em consideração duas estruturas fundamentais do (e co-originais com o) ser-no-mundo do Dasein,

${ }^{3}$ Cf. HEIDEGGER, Martin, op. cit., 114, p. 152.

${ }^{4}$ Cf. HEIDEGGER, Martin, op. cit., §§ 9-13, 40-62, p. 55-84

${ }^{5}$ Cf. HEIDEGGER, Martin, op. cit., 40-41, p. 55 e § 12, 53, p. 71

${ }^{6}$ HEIDEGGER, Martin, op. cit., § 12, 54, p. 73 ["In-Sein [...] meint eine Seinsverfassung des Daseins und ist ein Existenzial. Dann kann damit aber nicht gedacht werden an das Vorhandensein eines Körperdinges [...] 'in' einem vorhandenen Seienden. [...] 'in' stammt von innan-, wohnen, habitare [... ]; ' an' bedeutet: ich bin gewohnt, vertraut mit [...]. Dieses Seiende, dem das In-Sein in dieser Bedeutung zugehört, kennzeichneten wir als Seiende, das ich je selbst bin. Der Ausdruck 'bin' hängt zusammen mit 'bei'; 'ich bin' besagt wiederum: ich wohne, halte mich auf bei... der Welt [...]»]. 
nomeadamente: o ser-com e o ser-aí-com [Mitdasein] - modalidades existenciais sobre as quais repousa, de resto, a possibilidade geral do ser-simesmo. Vejamos, como tal, em que medida uma análise do ser-com e do seraí-com nos poderá ajudar a encontrar uma resposta para as nossas questões.

2 A estrutura formal e o significado existencial da questão pelo «quem?» do Dasein (Sein und Zeit, § 25)

No decurso do § 9 de Sein und Zeit, Heidegger havia já definido o Dasein como o ente que, em qualquer caso, eu próprio sou (e cujo ser é, correlativamente, o meu ser $)^{7}$. Aquele que é se autodetermina, assim, por via de uma explícita referência-a-si e deixa-se pensar, antes de mais, enquanto eu [ICh], enquanto sujeito [Subjekt], enquanto mesmo [Selbst]. Parece, por conseguinte, que a resposta à pergunta pelo «quem?» do Dasein está já previamente dada: o "quem» daquele que é reside na sua própria quididade, na sua própria essência [Was-sein/essentia], naquilo que se mantém idêntico perante a radical diversidade da experiência possível; o "quem» daquele que é deixa-se entender, numa palavra, como substância [Substanz]. O que quer isso dizer? Quer dizer, em primeiro lugar, que aquele que é-no-mundo está sendo formalmente interpretado por referência a uma essência já hipostasiada, surgindo desse modo como qualquer coisa jádeterminada que está presente-à-mão. Nesse contexto, a existência [Existenz] daquele que existe-no-mundo é pensada em função da categoria estática do ser-como-é [So-sein], e não em função do existencial ex-tático do ser-para [Zu-sein]; e a existência do Dasein, cujo sentido primário consiste numa livre projecção para os possíveis, é, como tal, subsumida num conjunto de categorias capazes de determinar a priori o «como?» [das Wie] daquele que é. A tradição metafísica pensou o Dasein como a posição ôntica de uma simples coisa entre as coisas, substituindo assim a questão fundamental pelo «quem?» daquele que existe por uma pergunta relativa ao "quê?» [das Was] das coisas que são. Em suma: interpretou-se o ser do Dasein como presença já-constituída [Ousia] e reduziu-se aquele que é-no-mundo a uma série de determinações ou de predicados presentes-à-mão; o Dasein é interpretado a partir da sua substancialidade - seja ela o espírito, seja o pensar -, tal como a mesa e a cadeira são teoreticamente interpretadas em função daquilo que subjaz às suas diversas determinações acidentais. 0 Dasein é, pois, assimilado a um presente-à-mão ${ }^{8}$.

\footnotetext{
${ }^{7}$ Cf. HEIDEGGER, Martin, op. cit., § 9, 41, p. 56.

${ }^{8}$ Cf. HEIDEGGER, Martin, op. cit., § 9, 42, p. 56-57 e § 25, 114-115 p. 153-154.
} 
Regressemos, no entanto, à questão pelo «quem?» do Dasein. Em que medida está ela sendo condicionada pelos conceitos de essência e de substância? Vejamos: diz-nos Heidegger que o eu=eu (ou referência-a-si) através do qual o Dasein se autodetermina é uma evidência ôntica aparentemente irrebatível. Eu sou aquele que é, e o é daquele que sou se determina, por conseguinte, como a posição ôntica de um puro eu-mesmo. Mas, o que é este eu indubitável e apodítico sobre o qual se alicerça a resposta autoreflexiva à questão pelo «quem?» do Dasein? Kant parece dizê-lo, com precisão, no § 16 da sua «Analítica dos Conceitos»:

\footnotetext{
O eu penso deve poder acompanhar todas as minhas representações; se assim não fosse, algo se representaria em mim que não poderia, de modo algum, ser pensado, que o mesmo é dizer que a representação ou seria impossível ou pelo menos nada seria para $\mathrm{mim}^{9}$.
}

O eu é, pois, para Kant, a garantia formal da coerência interna das representações de um puro sujeito transcendental; ele é uma unidade autorreflexiva que se institui como condição de possibilidade de um conteúdo de pensamento em geral. Todavia, e tal como justamente mostra Sartre, em "La Transcendance de l'ego», este «eu penso" parece revestir um carácter simplesmente condicional, porquanto «pode», por hipótese, acompanhar todas as minhas representações ${ }^{10}$. Ora, algo que está na possibilidade-de- $X$ encontra-se, de igual modo, confrontado com a possibilidade-de-não-X. Não é, portanto, necessário que este "eu penso» acompanhe, de facto, todas as minhas representações. E, mesmo que a unidade originariamente sintética da apercepção acompanhasse, realmente, todas as minhas representações, o eu assim obtido seria apenas o resultado da adscrição autorreflexiva e formal daquilo que é pensado àquele que pensa (= sujeito transcendental). Poderá essa autodoação reflexiva do eu revelar aquele que é na sua quotidianeidade? Que o mesmo é perguntar: poderá essa autodeterminação do eu, enquanto critério formal da unidade interna das minhas representações, vigorar ainda no quadro de uma analítica existencial do Dasein fáctico? Sejamos claros: segundo Heidegger, a tradicional

\footnotetext{
${ }^{9}$ KANT, Immanuel. Gesammelte Schriften, Berlin: Georg Reimer, 1911. v. III. Kritik der reinen Vernunft, § 16, b131-132 (Crítica da razão pura. Tradução Alexandre Fradique Morujão e Manuela Pinto dos Santos. Lisboa: Fundação Calouste Gulbenkian, 1997) [«Das: Ich denke, mu? alle meine Vorstellungen begleiten können; denn sonst würde etwas in mir vorgestellt werden, was gar nicht gedacht werden könnte, welches eben so viel hei?t, als die Vorstellung würde entweder unmöglich, oder wenigstens für mich nichts sein»].

${ }^{10}$ Cf. SARTRE, Jean Paul. La Transcendance de l'Ego. Esquisse d'une Description Phénoménologique. Recherches Philosophiques, Paris, v. 6, p. 85-123, 1936-1937.
} 
hipostasiação do eu como substrato unitário da diversidade do pensável parece estar inviabilizando a análise da dimensão fáctica e temporal daquele que é-no-mundo, na medida em que o eu autorreflexivo que a metafísica clássica arbitrariamente postula estatui aquele que é, num tempo e num espaço, como coisa já-constituída por referência a uma essência que o precede e determina onticamente. Mas porque, para Heidegger, «a 'essência“ do Dasein reside na sua existência» ${ }^{11}$, o suposto ser-como-é daquele que é deve agora ser pensado enquanto possibilidade de autodeterminação, ou seja, enquanto processo histórico e temporal de vir-a-ser. O que significa isso? Significa que o eu da tradição metafísica está revestindo agora o carácter de um constructo temporal, uma vez que já não se encontra determinado por uma substância capaz de condicionar a priori as diversas modalidades existenciais do Dasein:

\begin{abstract}
O "eu" deve ser compreendido apenas no sentido de um [... ] indicador formal, indicando qualquer coisa que talvez possa revelar-se como o seu "oposto" num qualquer particular contexto fenomenal de Ser. Nesse caso, o "não-Eu" não é, de modo algum, equivalente a um ente que essencialmente carece de "Ipseidade", mas é antes um modo de Ser definido que o próprio "Eu" possui, tal como ter-se-perdido-asi-mesmo ${ }^{12}$.
\end{abstract}

O não-eu não pode, por conseguinte, ser logicamente interpretado como uma mera infracção teórica do princípio de identidade (eu=eu), nem, tão-pouco, ser metafisicamente pensado como a posição (negativa) de uma ausência ou de um decréscimo de ser. Com efeito, e conforme Heidegger, o não-eu parece configurar um modo específico de ser, uma possibilidade de autodeterminação negativa do Dasein que, apenas à luz do processo ôntico de vir-a-ser-si-mesmo, poderá ser convenientemente compreendida. Porque o Dasein pode perder-se a si mesmo e falhar-se naquilo que é, ao longo da autoconstituição temporal daquele que ele próprio é; ele pode, em suma, ser aquele que ele não é e, correlativamente, não ser aquele que ele é. Em todo o caso, aquele que ele possa ser não está, de modo algum, já-dado como uma coisa previamente determinada. Levanta-se, pois, a questão: como poderemos, se verificada a impossibilidade de aplicarmos o modelo autorreflexivo à análise da efectividade temporal daquele que é, visar

${ }^{11}$ HEIDEGGER, Martin, op. cit., § 25, 116, p. 155 [«Das 'Ich' darf nur verstanden werden im Sinne einer [...] formalen Anzeige von etwas, das im jeweiligen phänomenalen Seinszusammenhang vielleicht sich als sein 'Gegenteil' enthüllt. Dabei besagt dann 'Nicht-Ich' keineswegs so viel wie Seiendes, das wesenhaft der 'Ichheit' entbehrt, sondern meint eine bestimmte Seinsart des 'Ich' selbst, zum Beispiel die Selbstverlorenheit»].

${ }^{12}$ Cf. HEIDEGGER, Martin, op. cit., §§ 14-24, 62-113, p. 85-151. 
tematicamente ao «quem» do Dasein? Na verdade, e tal como a seu tempo tratou de esclarecer a analítica heideggeriana da mundaneidade do mundo [Weltlichkeit der Welt] ${ }^{13}$, a autodoação do sujeito que é encontra-se dependente da prévia doação ontológica do mundo em-função-do-qual ele aparece como sendo. Assim, a pura referência-a-si ou auto-evidência reflexiva (e solipsista) do cogito cartesiano - que, como sabemos, parte da constituição da subjectividade pensante como res cogitans para posteriormente determinar o mundo como res extensa - inverte e subverte a ordem de razões que antecede e possibilita o surgimento ôntico daquele que é, descontextualizando-o por meio de uma explícita subtracção do seu ser-nomundo e das suas correlativas estruturas existenciais, a saber: o ser-com e o ser-aí-com ${ }^{14}$. A tarefa de pensar o «quem» do Dasein não pode, como tal, ser artificialmente discernida da tarefa de pensar o mundo (no qual ele sempre é) e os outros (com os quais e junto dos quais ele sempre está) porque, como muito bem escreve Heidegger, "[...] 'os Outros' já são aí connosco em Serno-mundo [...] $\|^{15}$. Vejamos, portanto, em que sentido uma análise ontologicamente apropriada (ou seja, existencial) do ser-aí-com e do sercom quotidiano nos poderá ajudar a surpreender os diversos modos de ser que estão concorrendo para a configuração fáctica do «quem» do Dasein.

3 A estrutura existencial e o significado formal do ser-com e do ser-aícom: o "freigebende Dasein» (Sein und Zeit, § 26)

A investigação empreendida por Heidegger nos §§ 14-24 de Sein und Zeit mostrou claramente que as relações estabelecidas entre o Dasein e o seu ambiente [Umwelt] implicam uma tácita referência aos outros. Na realidade, o sentido do equipamento [Zeug] e dos utensílios [zuhanden] que contribuem para a constituição do nosso mundo-de-trabalho [Werkwelt], e dos quais quotidianamente nos socorremos, deixa-se pensar por intermédio da "estrutura do reenvio» [verweisen $]^{16}$. Tal estrutura, por seu turno, acarreta a adscrição fáctica de um ser-para-qualquer-coisa, isto é, de uma função ou finalidade: um martelo é (ou serve) para pregar pregos na parede; uma tesoura é (ou serve) para cortar o tecido de um casaco. Ora, essa "estrutura do reenvio» que rege a utilização de um utensílio já envolve, de uma forma ou de outra, um mundo articulado de relações no contexto do qual os outros são

${ }^{13}$ Cf. HEIDEGGER, Martin, op. cit., §§ 18b-21, 88-102, p. 119-136.

${ }^{14}$ HEIDEGGER, Martin, op. cit., § 25, 116, p. 155-156 [«[...] 'die Anderen' je schon im Inder-Welt-sein mit da sind [...]»].

${ }^{15}$ Cf. HEIDEGGER, Martin, op. cit., § 18, 87, p. 117.

${ }^{16}$ Cf. HEIDEGGER, Martin, op. cit., § 9, 41-44, p. 56-59 e § 15, 69-72, p. 93-97. 
depreendidos como sendo (comigo): utilizo esta tesoura para cortar o tecido deste casaco, porque sou alfaiate e porque o meu cliente virá buscar o seu casaco ainda esta tarde; sirvo-me deste martelo para pregar estes pregos na parede, apenas porque alguém o fabricou e apenas porque alguém mo vendeu na loja de ferragens. Quer isto dizer, por conseguinte, que os utensílios são sempre apreendidos a partir da precedência de um ser-com que lhes confere uma significação e uma funcionalidade específicas. Ora, de acordo com a análise heideggeriana da mundaneidade do mundo, aquilo que estamos encontrando circunspectivamente no-meio-do-mundo [innerhalb-der-Welt] pode ser "arrumado» em função de dois modos fundamentais de ser: a) a Vorhandenheit, ou melhor, a natureza presente-à-mão e teoreticamente descritível e; b) a Zuhandenheit, ou melhor, o conjunto dos utensílios empregados na vida prática ${ }^{17}$. Podemos, no entanto, pensar o nosso próprio Dasein e o Dasein dos outros a partir desses dois modos fundamentais de ser? A resposta dada por Heidegger é clara a esse respeito:

\begin{abstract}
[...] o modo de Ser que pertence ao Dasein dos Outros, tal como o encontramos no-meio-do-mundo, difere do utensílio e da presençaà-mão. Assim, o mundo do Dasein liberta entes que não apenas são bastante distintos do equipamento e das Coisas, mas que também [...] são-no-mundo [...]. Estes entes são [...] como o próprio Dasein que os liberta, na medida em que também são aí, e aí com ele ${ }^{18}$.
\end{abstract}

A terminologia heideggeriana não poderia, neste caso, ser mais precisa: o Dasein liberta entes [gibt demnach Seiendes frei] que, tal como ele, são-no-mundo. O que significa isso? Procedamos como Heidegger e analisemos, antes de mais, os constituintes semânticos da forma verbal infinitiva de «gibt [...] frei» (partição da terceira pessoa do singular do presente do indicativo do verbo «freigeben»). Descobriremos, sem dificuldade, que "frei» significa «livre» e que «geben» significa "dar», "entregar», «conceder»; "dem», por sua vez, é o dativo do artigo definido masculino "den» (= "O»), ao qual se junta posteriormente a proposição «nach» (= «para»), a fim de formar a expressão compósita «demnach» (literalmente, "o-para»). Parece, em

\footnotetext{
${ }^{17}$ HEIDEGGER, Martin, op. cit., § 26, 118, p. 158 [«[...] die Seinsart des innerweltlich begegnenden Daseins der Anderen sich von Zuhandenheit und Vorhandenheit unterscheidet. Die Welt des Daseins gibt demnach Seiendes frei, das nicht nur von Zeug und Dingen überhaupt verschieden ist, sondern [...] In-der-Welt-seins [... ]. Dieses Seiende ist [...] wie das freigebende Dasein selbst - es ist auch und mit da»].

${ }^{18}$ Veremos, não obstante, como a concepção heideggeriana da intersubjectividade redunda, de maneira paradoxal, na redução da estrutura existencialmente constitutiva do ser-com a uma simples possibilidade de ser.
} 
decorrência, que a expressão "gibt demnach Seiendes frei» objetiva, simplesmente, designar algo como um «dar o ente (ou os outros) para o livre», sinalizando assim uma doação de liberdade, uma concessão de autonomia, em suma - um fazer livre, um efectivo entregar a liberdade a... O Dasein é, pois, um «freigebende Dasein»: aquele que dá (os outros) para o livre. Todavia, perguntemos: por que razão se encontravam os outros cativos antes dessa «doação de liberdade»? O que denota esse "fazer livre» através do qual o Dasein «entrega a liberdade aos outros» que, à sua imagem e semelhança, estão-sendo-no-mundo? Na verdade, segundo Heidegger, o processo ôntico que conduz à descoberta dos outros no mundo é sempre conduzido a partir do Dasein que eu próprio sou: sou eu quem descobre, sou eu quem desvela (os outros). Não é, portanto, a minha ipseidade que é revelada pela radical alteridade dos outros, mas antes a radical alteridade dos outros que é revelada pela minha ipseidade. Façamos, contudo, a devida justiça ao espírito da filosofia heideggeriana: não se trata aqui, de modo algum, de uma subjectividade solipsisticamente encerrada em si mesma, de uma caução formal da coerência interna das minhas representações ou de um mero substrato eidético de relações noético-noemáticas que, a título condicional, se confronta com a possibilidade de ser-com-outros ${ }^{19}$. A alteridade, salienta Heidegger, não é cognitivamente determinável por via de um processo de subtracção ou exclusão capaz de me contrapor a outros que apreenderia como não sendo aquele que sou. Bem pelo contrário, os outros são, em primeira instância, aqueles dos quais não nos distinguimos - aqueles entre os quais também somos ${ }^{20}$. Efectivamente, no quadro de Sein und Zeit, os outros não são tematicamente interpretados em função da categoria clássica da diferença, porquanto são aqueles com os quais me identifico, aqueles de quem me não distingo e com os quais partilho, de facto, uma mesma situação ôntica (ser-no-mundo) e um idêntico modo de ser (Dasein).

Qual é, então, a nosso ver, o "calcanhar de Aquiles» dessa interpretação da intersubjectividade? É, parece-nos, a explícita colocação do outro sob a égide do conceito do "também» $[A u c h]$, que supõe uma compreensão existencial da alteridade enquanto posição ôntica de algo como um ser-aítambém $[\text { Auch-da-sein }]^{21}$. Em rigor, este «também» através do qual a alteridade é por diversas vezes pensada, ao longo do § 26 de Sein und Zeit, reveste,

${ }^{19}$ Cf. HEIDEGGER, Martin, op. cit., § 26, 118, p. 158: «[... ] die Anderen sind vielmehr die, von denen man selbst sich [...] nicht unterscheidet, unter denen man auch ist».

${ }^{20}$ Cf. HEIDEGGER, Martin, op. cit., § 26, p. 118, p. 158.

${ }^{21}$ A nossa interpretação é, neste mesmo parágrafo de Sein und Zeit, explicitamente rebatida por Heidegger: "Als Mitsein ' ist' daher das Dasein wesenhaft umwillen Anderer. Das mu $ß$ als existenziale Wesenaussage verstanden werden». HEIDEGGER, Martin, op. cit., § 26, 123, p. 164 
claramente, o carácter de um indiferenciado, na medida em que aquilo que também é se deixa semanticamente entender como a simples enunciação de um acréscimo (contingente e dispensável) de ser. Quando, por exemplo, afirmo "fui ao cinema e também comi pipocas», a oração pela qual afirmo que utambém comi pipocas» parece designar apenas um complemento circunstancial de ser. Esse «também», por meio do qual dou a conhecer que "comi pipocas», quer assim dizer que o facto subordinado de as ter comido foi possibilitado pelo facto subordinante de ter ido ao cinema - pois, aquilo que também é se encontra sempre na estrita dependência de um é precedente. Como tal, ao mostrar que os outros «também» são-aí, Heidegger concentra definitivamente o foco da sua análise existencial sobre o Dasein em-função-do-qual esses outros «também» são-aí, com ele, no mundo ${ }^{22}$ :

[... ] a expressão "Dasein" mostra plenamente que [...] este ente não está relacionado com Outros e que ele pode ainda ser "com" Outros depois. Porém, não se deve deixar de notar que usamos o termo "Seraí-com" para designar esse Ser para o qual os Outros que são são libertados no-meio-do-mundo. Este Ser-aí-com dos Outros é desvelado no-meio-do-mundo para um Dasein - e, assim, também para aqueles que são Daseins connosco - apenas porque o Dasein é, em si mesmo, essencialmente Ser-com ${ }^{23}$

Poderíamos dizer, portanto, de acordo com Heidegger, que a abertura do Dasein aos outros não constitui um prévio-existencial ${ }^{24}$ desse ente que, em virtude da sua determinação fáctica enquanto ser-com, está necessariamente situado num mundo em que os outros já são. O Dasein é para si mesmo e, só depois, é para os outros; ele «pode» ser-com-outros, tal como a unidade originariamente sintética da apercepção deve "poder», segundo Kant, acompanhar todas as minhas representações. O ser-com heideggeriano expressa, por conseguinte, um condicional, um mero poderser que, justamente por essa razão, poderá de igual modo não ser. Não é, pois, necessário (mas antes possível) que o Dasein que está-sendo-no-mundo

${ }^{22}$ HEIDEGGER, Martin, op. cit., § 26, 120, p. 160-161 [«[...] der Ausdruck 'Dasein' zeigt doch deutlich, da $\beta$ dieses Seiende [...] ist in der Unbezogenheit auf Andere, da $\beta$ es nachträglich zwar auch noch 'mit' anderen sein kann. Es darf jedoch nicht übersehen werden, da $\beta$ wir den Terminus Mitdasein zur Bezeichnung des Seins gebrauchen, daraufhin die seienden Anderen innerweltlich freigegeben sind. Dieses Mitdasein der Anderen ist nur innerweltlich für ein Dasein und so auch für die Mitdaseinden erschlossen, weil das Dasein wesenhaft an ihm selbst Mitsein ist»] (grifos nossos).

${ }^{23}$ Acerca dos prévios-existenciais do Dasein (a saber: a disposição [Befindlichkeit], o compreender [verstehen], a interpretação [Auslegung] e a linguagem [Sprache]), cf. HEIDEGGER, Martin, op. cit., §§ 29-34, 134-167, p. 178-222.

${ }^{24}$ Cf. HEIDEGGER, Martin, op. cit., § 26, 123, p. 164-165. 
seja-aí com os outros, porquanto os entes que se deixam determinar facticamente pela estrutura existencial do ser-aí-com (os outros Daseins) configuram uma massa anónima e acéfala que sempre se refere ao ser «para o qual» são libertados no-meio-do-mundo, mais precisamente: o freigebende Dasein, esse ente que em virtude do seu ser-com concede aos outros o seu livre ser-para [Sein zu]. O que quer isso dizer? Quer dizer, em primeiro lugar, que o ser-com (estrutura existencial do Dasein) antecede e possibilita o aparecimento no mundo do ser-aí-com (estrutura existencial dos outros), uma vez que - tal como vimos - é, de facto, o Dasein quem norteia o encontro no mundo de uma alteridade em geral. Todavia, não esclarece Heidegger que esse Dasein que eu próprio sou, e que encontra os outros no-meio-domundo, é, por seu turno, um outro encontrado no-meio-do-mundo pelo Dasein dos outros? É certo que, do mesmo modo que o Dasein que sou "pode» encontrar os outros, igualmente o Dasein que os outros são «pode» encontrar o meu Dasein. Não nos equivoquemos, porém: esse «outros» de que (e não de quem, note-se) aqui se fala não constitui alguém que se encontre nomundo ou no-meio-do-mundo, na medida em que não corresponde a um Dasein individual (Pedro, Paulo ou Maria), visando antes a designar conceptualmente uma estrutura formal da existência que parece convergir, de forma indiscriminada, com todos aqueles que estão-sendo-no-mundo.

Eis-nos, assim, confrontados com o verdadeiro escolho da interpretação heideggeriana da intersubjectividade: esse Dasein que sou, todos os outros o são; e, correlativamente, esse «outros» que todos os outros são, também eu o sou para todos os outros; todos somos Dasein (em geral) e ninguém é Dasein (em particular) porque, na realidade, todos somos "outros» para o Dasein dos outros. Afirmar, assim, que os outros são aqueles com os quais me identifico e com os quais partilho um idêntico modo de ser (Dasein) significa certificar uma comunidade formal de existência, postular um conjunto vazio no seio do qual todos estamos juntos na nossa mútua indeterminação e indiferenciação. O Dasein liberta os outros, sustenta Heidegger. Mas, esse «outros» que ele assim liberta sanciona tão-só o abismo indistinto do ninguém que todos são:

\footnotetext{
Ser-com é uma característica do nosso próprio Dasein; Ser-aí-com caracteriza o Dasein dos Outros na medida em que é libertado pelo seu mundo para um Ser-com. O nosso próprio Dasein pode ser encontrado por Outros como Ser-aí-com apenas porque tem a estrutura essencial do Ser-com ${ }^{25}$.
}

${ }^{25}$ HEIDEGGER, Martin, op. cit., § 26, 121, p. 161 [«Mitsein ist eine Bestimmtheit des je eigenen Daseins; Mitdasein charakterisiert das Dasein Anderer, sofern es für ein Mitsein durch dessen Welt freigegeben ist. Das eigene Dasein ist nur, sofern es die Wesensstruktur des Mitseins hat, als für Andere begegnend Mitdasein»]. 
Quem é, no entanto, esse ente ao qual pertence essencialmente o ser-com? Quem é aquele que, sendo-no-mundo, liberta os outros para o seu ser-aí-com? Quem é, numa palavra, aquele que o Dasein é (quotidianamente)? Vejamos.

4 Em jeito de conclusão: do formalismo existencial do ser-com e do ser-aícom à impessoalidade acéfala do «eles» (Sein und Zeit, § 27)

A análise existencial do ser-com e do ser-aí-com, que Heidegger desenvolve no § 26 de Sein und Zeit, parece redundar, de facto, na sujeição formalista do outro ao conceito acéfalo e impessoal dos «outros». E, por "outros», entenda-se: aqueles que também são-aí, no meu mundo, apenas porque eu, o doador de liberdade, o freigebende Dasein, os libertei para o seu ser-livre. Mas, tal como vimos, ser é sempre ser-no-mundo, e ser-nomundo é sempre ser-com e ser-aí-com. O que significa isso? Significa, antes de mais, que a possibilidade de determinar tematicamente aquele que o Dasein é («quem?») está dependendo de uma prévia explicitação existencial dos seus diversos modos de ser (no mundo e com «outros»). Fui, sou e serei, na verdade, somente em função da forma como fiz, faço e farei o meu serno-mundo e o meu ser-com (a alteridade), pois aquilo que de facto sou aqui e agora - reveste o carácter de um projecto temporalmente lançado na senda de possíveis ainda-por-consumar. Perguntar pelo «quem?» daquele que é-no-mundo implica, então, perguntar em que sentido a relação estabelecida entre o Dasein e o Dasein dos outros (que também são-aí-com ele) estrutura existencialmente o seu ser-si-mesmo quotidiano. Ora, a determinação do ser-com como uma simples comunidade formal de existência parece conduzir, no § 27 de Sein und Zeit, a uma clara afirmação da distancialidade [Abständigkeit] como modalidade primária do ser-com ${ }^{26}$. Com efeito, aquele que eu próprio sou apreende os outros (e não, note-se, o outro) a partir da sua indiferenciação e indeterminação, isto é, como o conjunto impessoal e acéfalo de todos aqueles que são-aí-comigo, em suma: como «eles» [das Man]. A alteridade não é, pois, pensada por Heidegger em função da sua proximidade àquele que é-no-mundo: ela é, bem pelo contrário, expressamente identificada como o lugar do inevitável distanciamento de si consigo, da inevitável alienação e sujeição [Botmässigkeit] daquele que é; ela é a entidade (e não, note-se, o ente) que subtrai ao Dasein o seu «quem», a sua ipseidade, o seu ser-si-mesmo. Assim, perante esse "outros» ou esse «eles» que ninguém é, o Dasein não é, e nunca poderá vir a ser, aquele que ele próprio é, porquanto também é - ele mesmo - esse «outros» ou esse

${ }^{26}$ Cf. HEIDEGGER, Martin, op. cit., § 27, 126, p. 168-169. 
«eles» que ninguém é. É este, em rigor, o corolário lógico de uma concepção da intersubjectividade que está reduzindo a individualidade do outro à estrutura existencial (mas, ainda assim, formal) do ser-aí que todos somos e ninguém é:

Estes Outros, além do mais, não são Outros definidos. Pelo contrário, qualquer Outro pode representá-los. [...] "Os outros" que assim se designa, por forma a encobrir o facto de se lhes pertencer essencialmente em si mesmo, são aqueles que [...] "são-aí" no Seruns-com-os-outros quotidiano. O quem [do Dasein] é, não este, não aquele, não o próprio, não algumas pessoas [einige], e não a soma delas todas. O "quem" [do Dasein] é o neutro, o "eles" [das Man $]^{27}$.

Essa estratégia de autodesresponsabilização é, de resto, bem conhecida: em face da incapacidade de assumir plenamente o "quem» de quem sou, limito-me a projectar os putativos motivos da minha despersonalização (ou seja, do meu devir não-eu) sobre uma entidade difusa e intangível que me resgata do encargo quotidiano de conduzir a bom porto aquele que poderei vir-a-ser - se chego atrasado a uma reunião, a culpa foi dos transportes públicos; se descuido a educação dos meus filhos, a culpa foi da direcção da empresa, que me forçou a fazer horas extraordinárias; se, por fim, me alheio da coisa pública, a culpa foi da imprensa, que não me forneceu a informação adequada. A culpa foi e nunca é, e isto - essencialmente - porque aquele que é prefere depositar a sua responsabilidade [Verantwortlichkeit] no «eles» (ou seja, no «outros») em lugar de encarar nos olhos aquele que, à sua imagem e semelhança, é: o outro. Eis-nos, por conseguinte, confrontados com a imensa diferença que separa um pensar da dissolução do mesmo (eu e eles) de um pensar da relação com o outro (tu e eu). E, perante essa dicotomia, parece-nos redundante esclarecer de que lado da fronteira se encontra o pensamento do Heidegger de Sein und Zeit.

\footnotetext{
${ }^{27}$ HEIDEGGER, Martin, op. cit., § 27, 126, p. 168-169 ["Diese Anderen sind dabei nicht bestimmte Andere. Im Gegenteil, jeder Andere kann sie vertreten. [...] 'Die Anderen', die man so nennt, um die eigene wesenhafte Zugehörigkeit zu ihnen zu verdecken, sind die, die im alltäglichen Miteinandersein [...] ' da sind'. Das Wer ist nicht dieser und nicht jener, nicht man selbst und nicht einige und nicht die Summe Aller. Das 'Wer' ist das Neutrum, das Man»].
} 
MARQUES, Vasco Baptista. The same, the others and the "they". Trans/Form/ Ação, (Marília); v.33, n.2, p.129-142, 2010

ABSTRACT: The words that follow are an attempt to explore the various meanings that overlay the figure of the "with" [mit], such as it comes configured along the §§ 25-27 of Sein und Zeit. We will listen carefully to what Heidegger has to say about the necessary determination of the being-in-theworld [in-der-Welt-sein] as being-with [Mitsein], and see, then, to what extent does his existential analytic forces (or doesn't) the constitution of the being-one's-self [Selbstsein] to depend upon the figure of the other. Finally, and in conclusion, we will try to show how Heidegger articulates the question about the selfhood or about the "who?» [Wer?] of the everyday being-there [alltägliche Dasein] with a brief reflexion about the factical inauthenticity [Uneigentlichkeit] in which it often seems to sink. It will then be, we believe, the appropriate moment to discuss the meaning of the controversial Heideggerian notion of the "they" [das Man], also taking advantage of the opportunity to launch the question of the (ethical?) responsibility of the Dasein. In terms of method, we'll avoid (whenever possible) the traditional comments about the endless alternative ways of translating Heidegger's philosophical jargon.

KEYWORDS: Others. They. Being-there. With. World. Responsability.

\section{Referências}

HEIDEGGER, Martin. Gesamtausgabe. Frankfurt am Main: Vittorio Klostermann, 1977. v. II. Sein und Zeit (Being and time. Traduction John Macquarrie \& Edward Robinson. Oxford: Blackwell, 2001).

KANT, Immanuel. Gesammelte Schriften. Berlin: Georg Reimer, 1911. v. III. Kritik der reinen Vernunft (Crítica da Razão Pura. Tradução Alexandre Fradique Morujão e Manuela Pinto dos Santos. Lisboa: Fundação Calouste Gulbenkian, 1997).

SARTRE, Jean Paul. La Transcendance de l'Ego. Esquisse d'une description phénoménologique. Recherches Philosophiques, Paris, v. 6, p. 85-123, 1936 1937. 